\title{
Manifestation of non-ST elevation myocardial infarction due to hyperthyroidism in an anomalous right coronary artery
}

This article was published in the following Dove Press journal:

International Journal of General Medicine

8 November 2017

Number of times this article has been viewed

\author{
Vicken Zeitjian' \\ Carmel Moazez' \\ Mehrdad Saririan² \\ David L August ${ }^{3}$ \\ Ranjini Roy ${ }^{2}$ \\ 'Department of Internal Medicine, \\ 2Department of Cardiology, \\ ${ }^{3}$ Department of Radiology, Maricopa \\ Integrated Health System, Phoenix, \\ AZ, USA
}

Introduction: Anomalous origin of the right coronary artery (RCA) from the left coronary cusp of the aorta is a moderately rare but potentially life-threatening incident. Myocardial infarction (MI) and sudden cardiac death have been described with this anomaly, especially in those who engage in excessive exercise. However, this case study shows this incidence in association with hyperthyroidism.

Case description: A previously healthy 51-year-old female with history of hypothyroidism presented with acute onset chest pain for 1 day. Patient's electrocardiogram was normal, however, she had elevated troponins and given her typical chest pain, she was diagnosed with acute coronary syndrome (ACS). The patient had been on levothyroxine and was found to have a subnormal thyroid-stimulating hormone level suggesting hyperthyroidism. Echocardiogram was normal. Coronary angiogram showed an anomalous RCA arising from the left coronary cusp of the sinus of Valsalva and no evidence of atherosclerosis. A coronary computed tomography angiogram was done confirming this finding and showed a slit-like deformity of the coronary ostium with at least $50 \%$ luminal stenosis. The patient was referred to a cardiothoracic surgeon for potential coronary artery bypass graft.

Discussion: This case illustrates a rare presentation of ACS due to hyperthyroidism in an anomalous RCA. MI is a rare manifestation of hyperthyroidism, but in combination with an anatomical defect, it can potentiate adverse outcomes. The mechanisms by which thyroid hormones influence cardiovascular hemodynamics are by causing a hyperdynamic circulatory state, increasing myocardial oxygen demand, and increasing the risk of coronary vasospasm. The combination of anatomic and metabolic defects is what likely precipitated this patient's outcome. Keywords: hyperthyroidism, anomalous coronary artery, acute coronary syndrome, risk factors for acute coronary syndrome

\section{Introduction}

Myocardial infarction (MI) in the setting of hyperthyroidism is a rare but well-known phenomenon; however, association with adverse events in a patient with hyperthyroidism and an anomalous right coronary artery (RCA) has not been described in literature. Adverse events due to physical exercise in this type of anatomic anomaly have been reported as the most common cause of poor outcome requiring definitive surgical management. We describe the case of a patient with an anomalous RCA who presented with acute coronary syndrome (ACS) and hyperthyroidism. The discussion focuses on the clinical importance of hyperthyroidism in the subset of patients with this anatomic anomaly.
Correspondence: Vicken Zeitjian Maricopa Integrated Health System, 260I East Roosevelt Street, Phoenix, AZ 85008, USA

Email vicken.zeitjian@mihs.org 


\section{Case report}

A previously healthy 51-year-old Hispanic female with a significant history of hypothyroidism presented with acute onset chest pain for 1 day. She described the chest pain to be pressure-like in nature, retrosternal, and radiating to her left arm and shoulder without associated shortness of breath. She reported to be sitting at rest when the pain occurred suddenly. She has been an active individual most of her life, but has had intermittent chest pain with exertion for the past 2 months. She has had to stop exercise for relief and has minimized her physical activity. The chest pain on presentation was reported to be similar in nature to the chest pain she had previously. According to the patient, she did not have any syncope, palpitations, racing of the heart, lightheadedness, anxiety, diarrhea, weight loss, or brittle hair. The reason she sought medical care this time was due to increased severity of pain.

Two months prior to presentation, she was diagnosed with hypothyroidism with a thyroid-stimulating hormone (TSH) level of $\sim 500 \mathrm{U} / \mathrm{mL}$ and given levothyroxine $137 \mathrm{mcg}$ daily. The dose was reduced a few days after labs indicated supranormal triiodothyronine (T3) and thyroxine (T4) levels, but low TSH after starting the medication. She had most recently been on levothyroxine $100 \mathrm{mcg}$ daily, which she was compliant with. She also reported taking omeprazole $20 \mathrm{mg}$ daily for gastroesophageal reflux disease. She did not use oral contraceptive pills. She has never had hypercholesterolemia and had a negative fasting lipid panel from $\sim 1$ year prior to presentation. She denied any other past medical or surgical history. She does not have allergies. She was a lifelong nonsmoker, did not consume alcohol, and did not use illicit drugs.

On presentation, her vitals were normal. Her BMI was $27.3 \mathrm{~kg} / \mathrm{m}^{2}$. The physical exam is only significant for a woman who appears in her stated age in mild distress due to chest pain. The electrocardiogram was consistent with normal sinus rhythm without any abnormalities. Troponins were elevated and trended upward from 0.080 to 0.120 to $0.222 \mathrm{ng} / \mathrm{mL}$ each 8 hours apart. TSH was nearly undetectable at $<0.015$ $\mathrm{U} / \mathrm{mL}$ consistent with hyperthyroidism. T3 and T4 were not measured on presentation. Levothyroxine was stopped. Chest $\mathrm{x}$-ray was unremarkable. Bedside 2D echocardiogram showed a normal left ventricle with EF of $>60 \%$ without any regional wall motion abnormalities. The left atrium was mildly dilated, and right ventricular systolic pressure was 32 mm Hg. Non-ST elevation MI was diagnosed and patient was given atorvastatin $80 \mathrm{mg}$, heparin drip, clopidogrel 600 $\mathrm{mg}$, and aspirin $324 \mathrm{mg}$. Sublingual nitroglycerin $0.4 \mathrm{mg}$ was given, which improved the chest pain from a 10/10 on presentation to a $6 / 10$. Coronary angiogram was done on the day of presentation, which showed an anomalous RCA arising from the left coronary cusp of the sinus of Valsalva, but no evidence of occlusion (Figures 1 and 2).

A follow-up coronary computed tomography angiogram was done, which confirmed this finding and showed the anomalous RCA taking an inter-arterial course originating from the coronary ostium with a slit-like deformity and at least 50\% luminal stenosis (Figure 3).

Troponins trended downward and chest pain resolved. Due to known poor outcomes with this type of symptomatic

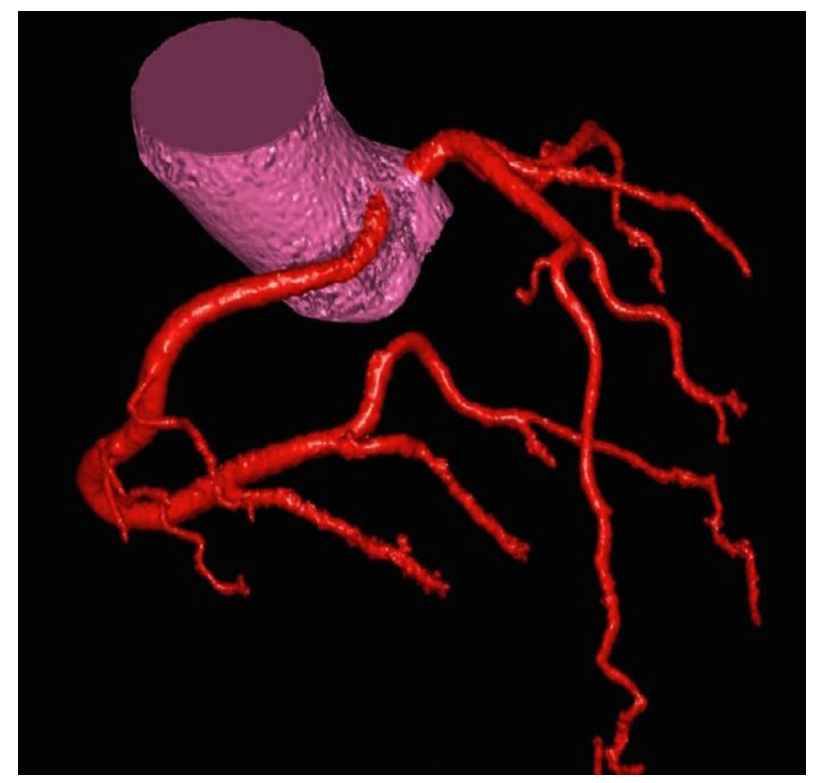

Figure I Coronary angiogram depicted in color to show origination of right and left coronary arteries from the left aortic cusp.

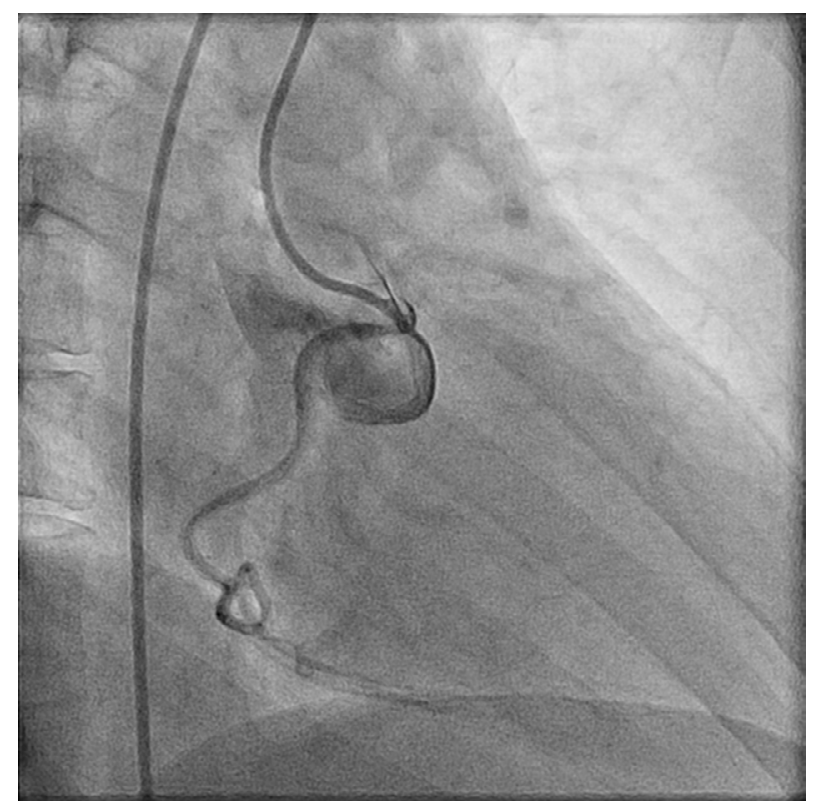

Figure 2 Real-time coronary catheterization fluoroscopic image demonstrating unilateral origination of both coronary arteries. 


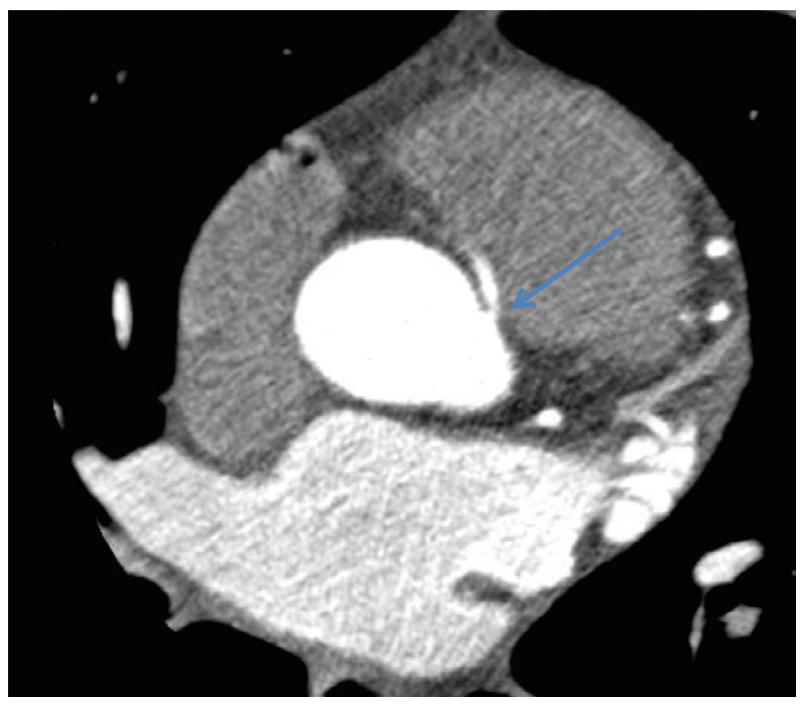

Figure 3 CCTA showing a slit like opening with $50 \%$ stenosis of the anomalous RCA from the left coronary cusp.

Abbreviations: CCTA, coronary computed tomography angiogram; RCA, right coronary artery.

coronary anomaly, the patient was referred to a cardiothoracic surgeon for definitive surgical correction. The patient was discharged home with levothyroxine $50 \mathrm{mcg}$ daily, metoprolol $25 \mathrm{mg}$ BID, and recommendation against aggressive physical activity.

\section{Consent}

Informed consent was obtained from the patient for publication of this case report and any accompanying images.

\section{Discussion}

It is well known that hyperthyroidism is associated with cardiovascular abnormalities as well as abnormal hemodynamic parameters. ${ }^{1}$ On more rare occasions, MI has been described as a potential complication with an incidence of $1.8 \% .^{2}$ In the setting of an anomalous RCA with a slit-like deformity, we speculate an increase in adverse event, which may require a more aggressive approach for definitive management of the anatomic anomaly.

Hyperthyroidism has been proposed to have a direct effect on coronary arteries due to a hyper-metabolic state resulting most commonly in atrial fibrillation, supraventricular tachycardia, and coronary vasospasm. ${ }^{3}$ An increase in thyroid hormone results in increased numbers and increased sensitivity of adrenergic receptors on the myocardium and on the coronary arteries. For this reason, cardiovascular hemodynamics are altered resulting in tachycardia, palpitations, hyperdynamic precordium, increased cardiac output, widened pulse pressure, and anginal chest pain. Another mechanism by which increased thyroid hormone predisposes to ischemia is by creating a hypercoagulable state. Hyperthyroidism has been reported to raise concentrations of von Willebrand Factor, Factor 8, and Factor 9; increase platelet plug formation and levels of plasma fibrinogen and plasminogen activator inhibitor; and decrease levels of tissue plasminogen activator. Thyroid hormone upregulates gene transcription of hepatic and endothelial cells. ${ }^{4,5}$ Although less common than the typical risk factors for coronary artery disease such as dyslipidemia, smoking, and diabetes, hyperthyroidism has been reported in many cases to be an independent risk factor as well. ${ }^{6}$ In addition, a hyperthyroid state in addition to a pre-existing risk factor has been shown to manifest acute thrombosis. $^{7}$

MI and sudden cardiac death (SCD) have been associated with anomalous coronary arteries. They are most often associated with an anomalous left coronary artery given the anatomic nature of supplying higher oxygen-demanding tissues. However, anomalous RCAs are incidentally found more frequently. ${ }^{8}$ The incidence of an anomalous RCA arising from the left coronary cusp that courses between the great vessels as in our patient varies from $0.026 \%$ to $0.250 \% .^{9}$ In general, coronary artery anomalies are considered benign in $80.6 \%$ of cases and potentially serious in $19.4 \%$ of cases as described in a study by Yamanaka and Hobbs. Identification of these clinically insignificant and benign coronary arteries is done by angiographic incidence. ${ }^{10}$ Proposed mechanisms of ischemia resulting in MI or SCD are: 1) acute angulation at the ostium of the coronary artery, 2) an abnormal slit-like opening, 3) mechanical compression of the anomalous artery when coursing between the aorta and pulmonary artery on exertion, and 4) vasospasm of the anomalous artery. ${ }^{11-13}$ The management of an incidental anomalous RCA is conservative; however, the challenge is to identify when the ischemic threshold is surpassed requiring surgical correction. Analyzing this threshold by considering risk factors and clinical presentation may guide management.

Our patient had several atypical risk factors for developing ACS. Although dyslipidemia, smoking, and diabetes were not in her risk profile, the combination of a slit-like deformity with 50\% stenosis, a malignant inter-arterial course of the anomalous RCA in between the great vessels (Figure 4), and a hyperthyroid state resulted in ischemia.

She had recently been diagnosed with hypothyroidism and started on levothyroxine, which is likely the factor that caused her hyperthyroid state and exacerbated her predisposition to ACS. One interesting finding between hyperthyroidism and this anatomic defect is each condition's predisposition 


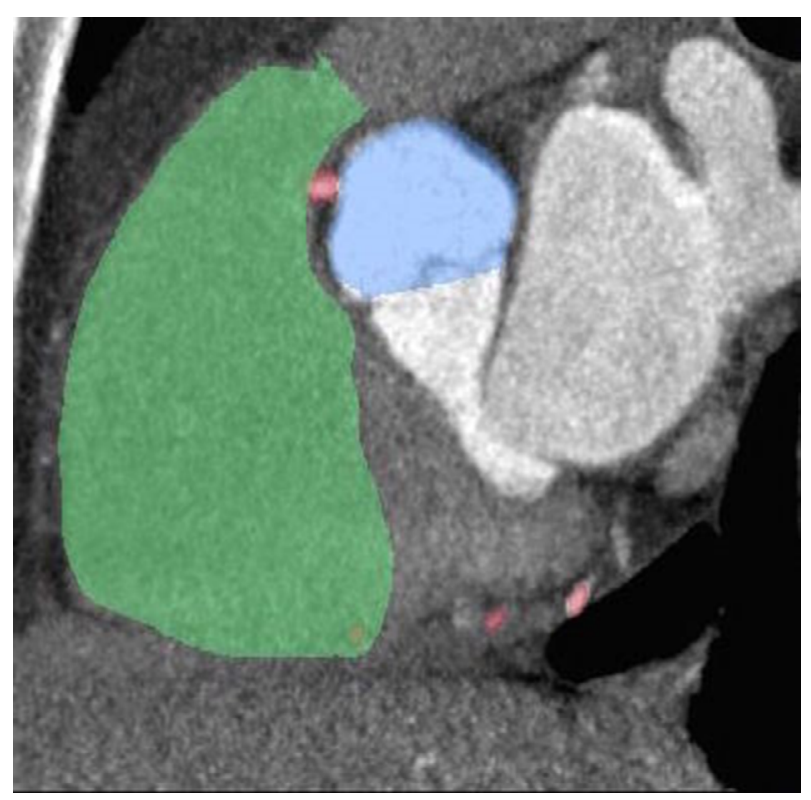

Figure 4 CCTA showing the right coronary artery taking a posterior inter-arterial course between the aorta and pulmonary trunk.

Abbreviation: CCTA, coronary computed tomography angiogram.

to coronary vasospasm. Coronary spasm is an independent mechanism proposed in each disease, which when combined can potentiate its likelihood. Coronary spasm is typically reversible which responds well to nitroglycerin, calcium channel blockers, and decrease in exertion. ${ }^{2}$ This was seen in our patient who had chest pain improvement with sublingual nitroglycerin. The pathophysiology of ACS in our patient is likely due to one of two mechanisms: 1) compression of the RCA from a hyperdynamic precordium between the great vessels due to the hyperthyroid state and 2) diffuse coronary vasospasm with potentiation of ischemia of RCA territory. While the anomalous RCA is itself the more significant risk factor, it is uncommon for it alone to present as ACS.

In considering management, it is important to remember that SCD has been reported in patients with anomalous coronary arteries who often presented $62 \%$ of the time without symptoms. ${ }^{14}$ In making an ultimate decision in surgical versus medical management of concurrent hyperthyroidism and anomalous RCA, it is important to consider other risk factors such as age, sex, presence of smoking, diabetes, hypertension, dyslipidemia, obesity, psychosocial factors, family history, and prior MI. ${ }^{15}$

\section{Limitations}

For improvement in future diagnosis of hyperthyroidisminduced ACS, it is important to also check initial T3 and free T4 levels as markers to differentiate a state of subclinical hyperthyroidism versus overt hyperthyroidism. For our patient, these values were not initially checked, and subsequent ones 2 days after presentation when levothyroxine was stopped were in the normal range. However, given her presentation and history, her thyroid disease best explains the cause of the ACS. Prognostic implications and management of subclinical states of thyroid disease are controversial and continue to be studied. ${ }^{16,17}$

\section{Conclusion}

This case highlights the risk of MI in a patient without typical risk factors and with an otherwise asymptomatic anomalous RCA upon onset of hyperthyroidism. We suspect that the patient's anatomic anomaly in combination with her hyperthyroid state increased her risk for adverse event. Therefore, although management of an asymptomatic anomalous RCA is often conservative, it is crucial to consider co-existing risk factors, which may exacerbate this potentially fatal condition.

\section{Disclosure}

The authors report no conflicts of interest in this work.

\section{References}

1. Osman F, Franklyn JA, Holder RL, Sheppard MC, Gammage MD. Cardiovascular manifestations of hyperthyroidism before and after antithyroid therapy: a matched case-control study. J Am Coll Cardiol. 2007;49(1):71-81.

2. Gupta M, Pradhan D, Jian S, Chen L, Fei L, Sharma B. Acute myocardial infarction associated with thyrotoxicosis. J Clin Case Rep. 2013;3:5.

3. Masani ND, Northridge DB, Hall RJ. Severe coronary vasospasm associated with hyperthyroidism causing myocardial infarction. Br Heart J. 1995;74(6):700-701.

4. Erem C, Ersoz HO, Karti SS, et al. Blood coagulation and fibrinolysis in patients with hyperthyroidism. J Endocrinol Invest. 2002;25(4): 345-350.

5. Homoncik M, Gessl A, Ferlitsch A, Jilma B, Vierhapper H. Altered platelet plug formation in hyperthyroidism and hypothyroidism. J Clin Endocrinol Metab. 2007;92(8):3006-3012.

6. Malarkiewicz E, Dziamalek P, Konsek S. Myocardial infarction as a clinical manifestation of hyperthyroidism. Polish Ann Med. 2015;22(2):139-142.

7. Lewandowski KC, Rechciński T, Krzemińska-Pakula M, Lewiński A. Acute myocardial infarction as the first presentation of thyrotoxicosis in a 31 year old woman. Thyroid Res. 2010;3(1):1.

8. Gersony WM. Management of anomalous coronary artery from the contralateral coronary sinus. $J$ Am Coll Cardiol. 2007;50(21): 2083-2084.

9. Carboni GP, Sedati P. Inducible myocardial ischemia and anomalous origin of the right coronary artery coursing between the aorta and pulmonary artery: a rare, sinister entity. BMJ Case Rep. 2012;2012:pii: bcr0220125884.

10. Yamanaka O, Hobbs RE. Coronary artery anomalies in 126,595 patients undergoing coronary arteriography. Catheter Cardiovasc Diagn. 1990;21(1):28-40.

11. Basso C, Maron BJ, Corrado D, Thiene G. Clinical profile of congenital coronary artery anomalies with origin from the wrong aortic sinus leading to sudden death in young competitive athletes. $\mathrm{J} \mathrm{Am} \mathrm{Coll} \mathrm{Cardiol}$. 2000;35(6):1493-1501. 
12. Ho J, Strickman N. Anomalous origin of the right coronary artery from the left coronary sinus. Tex Heart Inst J. 2002;29(1):37-39.

13. Lee BY.Anomalous right coronary artery from the left coronary sinus with an interarterial course: is it really dangerous? Korean Circ J. 2009;39(5): 175-179.

14. Taylor AJ, Rogan KM, Virmani R. Sudden cardiac death associated with isolated congenital coronary artery anomalies. $\mathrm{J} \mathrm{Am} \mathrm{Coll} \mathrm{Cardiol}$. 1992;20(3):640-647.
15. Yusuf S, Hawken S, Ounpuu S, et al; INTERHEART Study Investigators. Effect of potentially modifiable risk factors associated with myocardial infarction in 52 countries (the INTERHEART study): case-control study. Lancet. 2004;364(9438):937-952.

16. Biondi B, Cooper DS. The clinical significance of subclinical thyroid dysfunction. Endocr Rev. 2008;29(1):76-131.

17. CooperDS, Biondi B. Subclinical thyroid disease. Lancet. 2012;379(9821): $1142-1154$.
International Journal of General Medicine

\section{Publish your work in this journal}

The International Journal of General Medicine is an international peer-reviewed open-access journal that focuses on general and internal medicine, pathogenesis, epidemiology, diagnosis, monitoring and treatment protocols. The journal is characterized by the rapid reporting of reviews, original research and clinical studies across all disease areas.

\section{Dovepress}

The manuscript management system is completely online and includes a very quick and fair peer-review system, which is all easy to use. Visit http://www.dovepress.com/testimonials.php to read real quotes from published authors.

Submit your manuscript here: https://www.dovepress.com/international-journal-of-general-medicine-journal 